\title{
Initial Stages in the Formation of Galls Induced by Geoica utricularia in Pistacia Terebinthus Leaflets: Origin of the Two Vascular Bundles Which Characterize the Wall of the Galls
}

\begin{abstract}
Álvarez Nogal
Biología Celular, Universidad de León, León, Spain.

Email: ralvn@unileon.es

Received April $9^{\text {th }}, 2011$; revised April 23 $3^{\text {rd }}, 2011$; accepted May $5^{\text {th }}, 2011$.

ABSTRACT

Only a few species of aphids induce galls. Among these, Paracletus cimiciformis, Forda marginata, Forda formicaria, Geoica utricularia and Baizongia pistaciae induce galls on Pistacia terebinthus leaflets. Prior to present study the author examined microscopically P. terebinthus leaflets. He also studied the microscopic morphology of galls induced by the five species mentioned above. A clear microscopic difference between these galls is that in the wall of galls induced by the genera Paracletus and Forda a single vascular bundle is seen. The interpretation is that these galls are laminae of the modified leaflets. However, in the walls of the galls induced by the genera Geoica and Baizongia, two vascular bundles are observed. In the present paper a study of the early stages of development of galls produced by G. utricularia is described. The study was designed to explain the origin of the two vascular bundles present in the walls of these galls. The findings indicate that the aphid induces a massive development of the two vascular bundles present in the midvein of the leaflets of P. terebinthus: the main vascular bundle and the small supernumerary vascular bundle. Both these extremely developed vascular bundles occupy the walls of the galls induced by G. utricularia.
\end{abstract}

Keywords: Microscopic Study, Galls, Gallicolous Aphids, Geoica Utricularia, Pistacia Terebinthus, Vascular Bundles

\section{Introduction}

Aphids are insects that feed on the phloem sap that flows through the plant $[1,2]$. Most aphids live in populations in the open air. Only a few species (the Eriosomatinae) form galls on host plants. The structure of the galls is controlled by the aphids themselves [3]. Gall-inducing aphids do not eat the tissue of the host, but they reorganize the vascular tissues to be able to access them easily [4]. Among the species of gall-forming aphids, G. utricularia induces galls on leaflets of plants of the genus Pistacia.

P. terebinthus is found in the study area. On these shrubs at least five different galls can be identified - according to Inbar et al. [5] - induced by as many aphid species (all belonging to the tribe Fordini): P. cimiciformis, F. marginata, F. formicaria, G. utricularia, and B. pistaciae. They are prosoplasmatic galls, i.e. they have a defined size and shape and show a clear tissue differentiation [6]. They are also monothalamic galls, i.e. they have only one chamber [7,8]. The first three types of galls are formed as a fold in the leaflet margins. The other two types are voluminous galls and are balloon-shaped or banana or goat horn-shaped, respectively $[9,10]$. Prior to the present study, the author microscopically examined the normal morphology of P. terebinthus leaflets [11]. Subsequently the same author microscopically studied galls induced by $P$. cimiciformis, $F$. marginata, and $F$. formicaria [9]. And recently, he studied the walls of the galls induced by G. utricularia and B. pistaciae [10]. The microscopic morphology of the galls induced in the leaflet margin is different from that induced by the genera Geoica and Baizongia: in the wall of the galls of the first three species there is only one vascular bundle, whereas in the wall of the galls of the other two species two vascular bundles are observed $[9,10]$. This structural difference supports the existence of two clades within the tribe Fordini, in agreement with several authors $[5,12]$. In addition, in the galls induced by the genera Paracletus and 
Forda the xylem is oriented toward the lumen of the gall. Aphids inside the chamber of the gall must circumvent the xylem or pass through it to reach the phloem. In galls induced by the genera Geoica and Baizongia, the vascular bundle farthest removed from the lumen of the gall positions itself in the same way as the one before it. However, the second vascular bundle is positioned opposite the first (xylem facing xylem), leaving the phloem oriented toward the lumen of the galls $[9,10]$.

In the present paper, newly formed and young galls of G. utricularia are analyzed microscopically, in order to learn the origin of the two vascular bundles present in the walls of these galls.

\section{Material and Methods}

Essentially the same protocol was followed as used in 3 previous studies by the same author [9-11].

Galls on P. terebinthus induced by aphids of the species G. utricularia were collected from the wild. Samples were taken in April and May at sites in the west of the province of León (Spain). Samples were collected from the early stages of development of the galls, from incipient galls to young galls (Figures 1(a)-(e)). The corresponding uninfested (control) leaflets were also collected. Samples were placed in situ in FAA (formaldehyde, acetic acid, and ethyl alcohol) and were fixed for 48 hours. They were subsequently dehydrated through an increasing ethyl alcohol series, passed through isoamyl acetate as an intermediate liquid, impregnated with Paraplast for 90 minutes in an oven at $64^{\circ} \mathrm{C}$, and finally blocks were formed. Of these blocks, $12 \mu \mathrm{m}$ thick serial sections were obtained using a paraffin microtome. The Safranin-Fast Green staining method was used. The preparations were mounted permanently on microscope slides with Entellan.

Preparations were studied using a Nikon E600 microscope under bright-field, epi-fluorescence, and polarized light conditions.

\section{Results}

In the midvein of young $P$. terebinthus leaflets, 8 areas can be distinguished (Figure 1(f)): 1/abaxial epidermis; 2/annular collenchyma ( $2-3$ rows of cells); $3 /$ storage parenchyma; 4/main vascular bundle: collateral bundle with conspicuous schizogenic ducts in the phloem and abundant xylem elements; $5 /$ storage parenchyma; 6/supernumerary vascular bundle: collateral bundle with few xylem elements and no schizogenic ducts in the phloem. The 7/storage parenchyma; and 8/adaxial epidermis are facing the main vascular bundle (Figure 1(g)).

In the first stages of development of the galls (Figure 1(h)) a higher cellularity is observed than in the control leaflets. This increased number of cells is evident in the parenchyma. In addition, the supernumerary vascular bundle presents more xylem elements than the control leaflets. Unicellular trichomes were observed in the epidermis lining the chambers of the galls (Figures 1(c)-(d)). Subsequently (Figure 1(i)) an increase is observed in the number of cells of the three parenchyma layers considered. The vascular bundles are very developed, and show an evident procambium. At a later stage, the increased cellularity is evident (Figure 1(j)). The development of the two vascular bundles is also evident, and a prominent procambium is observed in both. The generalized hypertrophy causes a displacement of the midvein with respect to control leaflets. It can be seen how the two vascular bundles enter the wall of the gall (Figure 2). Specifically, it can be observed that the main vascular bundle occupies the outermost part of the wall. The supernumerary vascular bundle occupies the innermost part of the wall, i.e. the part closest to the lumen of the gall. Unicellular trichomes are located exclusively in the most proximal part of the galls.

\section{Discussion}

Only a few species of aphids induce galls. Among them, G. utricularia forms spherical galls on the abaxial side of $P$. terebinthus leaflets.

Prior to the present study, the author did a histological study of the leaflets on which these galls are found. Of that study, it should be noted here that the leaflets of $P$. terebinthus have pinnate venation, i.e. a main midvein or midrib $[11,13]$. Specifically, in the midvein of the leaflets of $P$. terebinthus two vascular bundles can be observed microscopically: one primary vascular bundle and one supernumerary vascular bundle with few elements. Both are collateral vascular bundles. Xylem is seen facing $\mathrm{xy}$ lem, separated by few parenchyma cells. The phloem of the supernumerary bundle is oriented toward the adaxial side of the leaflet, and the phloem of the main vascular bundle is oriented toward the abaxial side.

Subsequently, galls induced by $P$. cimiciformis, $F$. marginata, and $F$. formicaria in the margins of the leaflets of $P$. terebinthus were studied microscopically [9]. Such galls can be understood as laminae of the modified leaflets. A single vascular bundle, developed to a greater or lesser extent, is observed in them: the phloem is oriented toward the outside of the gall, and the xylem is oriented toward the lumen of the chamber. That is, the veins, with varying degrees of hypertrophy, of the lamina itself are observed in them. These are veins in which the small supernumerary vascular bundle that characterizes the midvein of the leaflets of $P$. terebinthus is not observed. Next, the walls of the galls induced by G. utricularia 


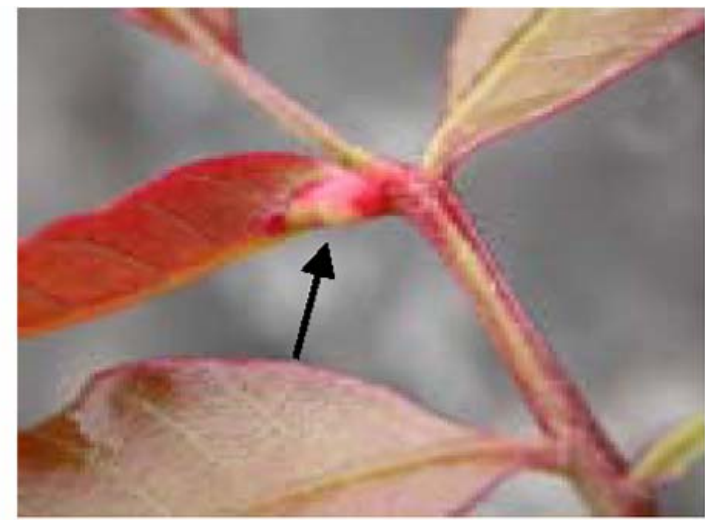

(a)

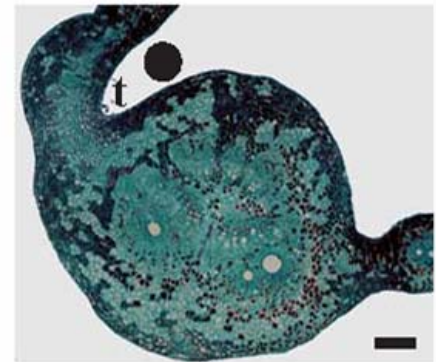

(c)

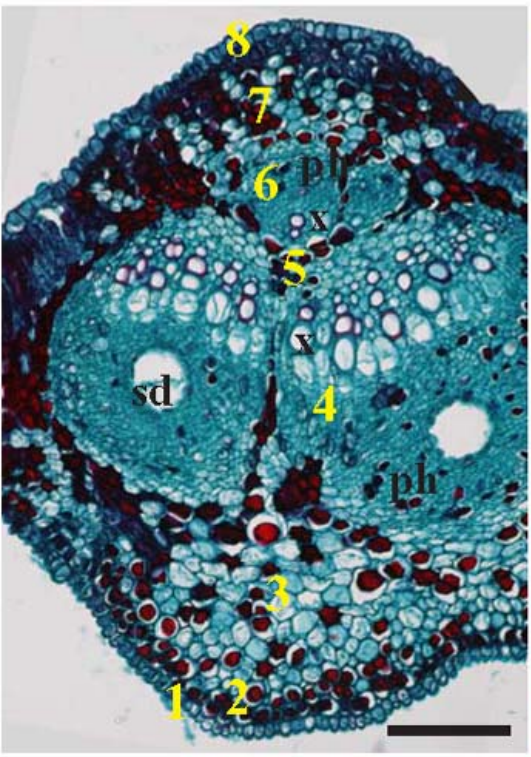

(f)

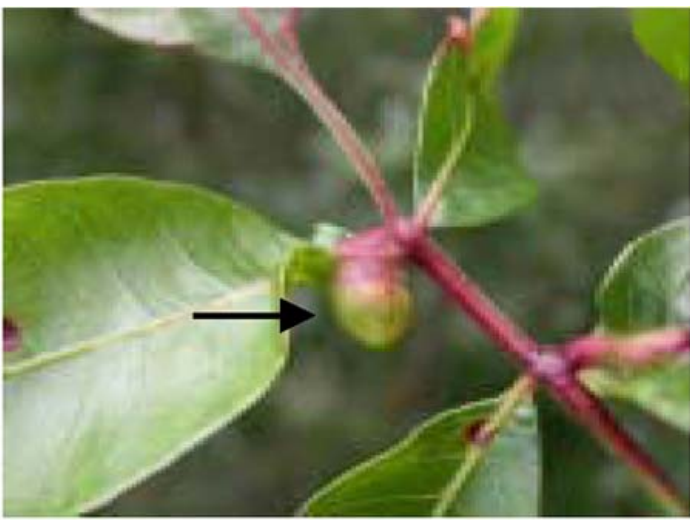

(b)

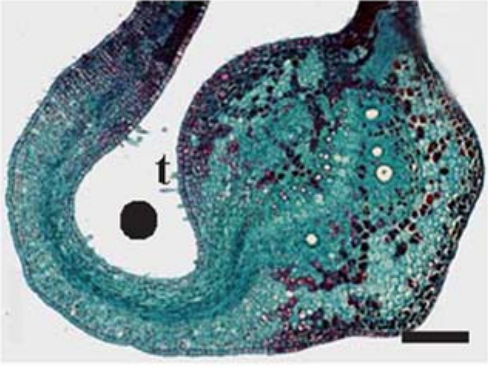

(d)

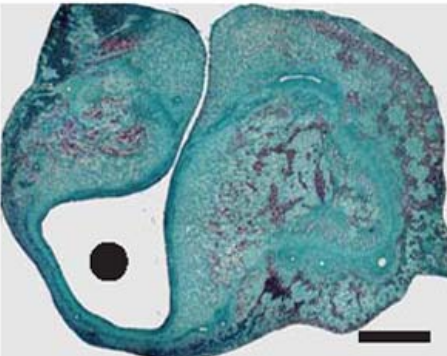

(e)

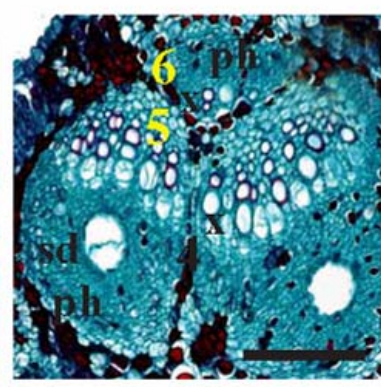

(g)

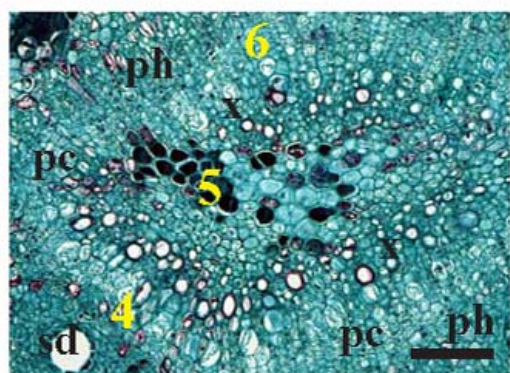

(i)

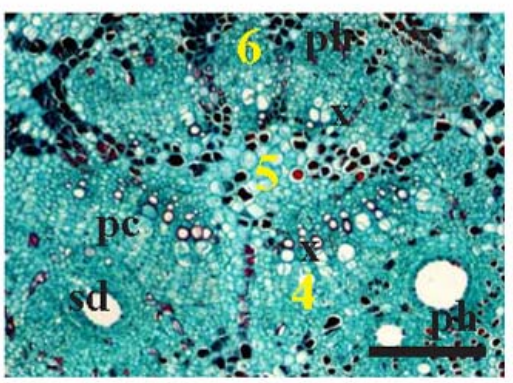

(h)

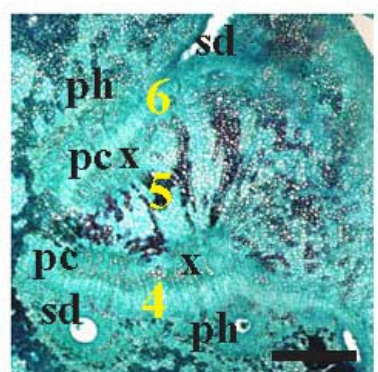

(j)

Figure 1. Pistacia terebinthus leaflets bearing galls (arrows) induced by Geoica utricularia (a, b). An incipient gall is shown in (a), and a young gall is shown in (b). Microscopic sections of galls induced by Geoica utricularia (c-e). The dot indicates the evolution of the chamber of the gall. Transverse section of the midvein of the leaflet of Pistacia terebinthus (f). Detail of the midvein shown in (f, g). Evolution of the midvein of leaflets bearing galls $(h-j)$, from initial stages (h) to young galls $(j)$. (c-j) Safranin-Fast Green. Bright-field light microscopy. Numbers and abbreviations: 1, abaxial epidermis; 2, collenchyma; 3 , abaxial parenchyma; 4, main vascular bundle; 5, parenchyma between bundles; 6 , supernumerary vascular bundle; 7 , abaxial parenchyma; 8, adaxial epidermis; pc, procambium; ph, phloem; sd, schizogenic duch; t, trichomes; $x$, xylem. Scale bars $(c, f, g)=100 \mu \mathrm{m} ;(d, h, i)=200 \mu \mathrm{m} ;(j)=500 \mu \mathrm{m} ;(e)=1000 \mu \mathrm{m}$. 


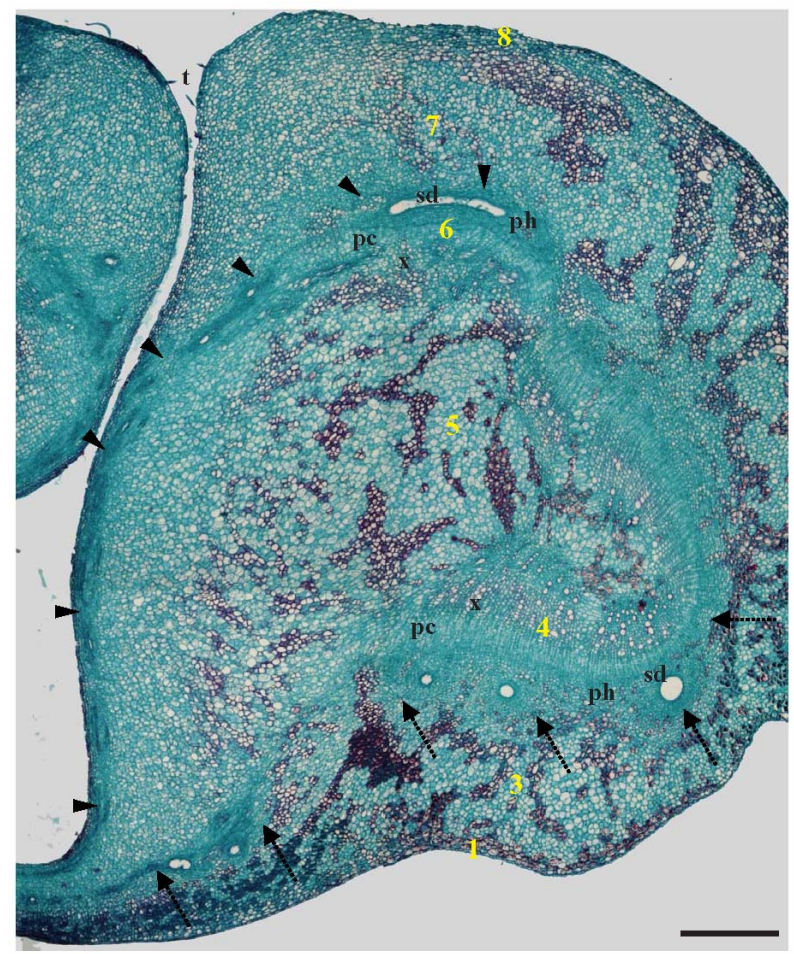

Figure 2. Young gall induced by Geoica utricularia. Note the development of the primary vascular bundle (arrows) and the supernumerary vascular bundle (arrowheads). Safranin-Fast Green. Bright-field light microscopy. Numbers and abbreviations: 1, abaxial epidermis; 3, abaxial parenchyma; 4 , main vascular bundle; 5 , parenchyma between bundles; 6 , supernumerary vascular bundle; 7 , abaxial parenchyma; 8, adaxial epidermis; pc, procambium; ph, phloem; sd, schizogenic duch; t, trichomes; $x$, xylem. Scale bar $500 \mu \mathrm{m}$.

and B. pistaciae were studied [10]. These walls have two vascular bundles, and not just one as seen in the galls studied before. The question that gave rise to the present study related to the origin of the two vascular bundles seen in the walls of the galls induced by $G$. utricularia. To this end, newly formed galls and young galls were analyzed microscopically and compared with the leaflets of $P$. terebinthus.

The two -hypertrophied- vascular bundles present in the midvein of the leaflets of $P$. terebinthus occupy the walls of the galls induced by G. utricularia. This is demonstrated not only by the detailed study of the serial sections, but also by the study showing that the two vascular bundles in the wall of the gall are facing each other. Just like the supernumerary vascular bundle and the main vascular bundle in the midvein of the leaflets of $P$. terebinthus are facing each other [11]. The fact that a prominent procambium is observed in the two vascular bundles provides further support.
Several authors have made comparisons between the lamina of the leaflets of the genus Pistacia and the walls of the galls induced by species of the genus Geoica $[4,14]$. In view of the results of the present study, such a comparison may not be correct. However, it does make sense to make such a comparison regarding galls induced by aphids in the genera Paracletus and Forda [9]. Therefore, the structure of galls induced by G. utricularia should be compared with the midveins of the leaflets of $P$. terebinthus. Or, to say it differently, the galls induced by $G$. utricularia are structures depending on the midvein of the leaflets. This observation is in agreement with the suggestion of Inbar et al. [5] that the subtribe Baizongiini (which includes the genus Geoica) evolutionarily acquired the ability to develop large galls on the midvein. In the absence of microscopic studies, these findings do not contradict the suggestion of Remaudière et al. [15]. These authors state that G. swirskii forms a gall on $P$. atlantica in the leaf rachis but not on the midvein of these leaflets, and not in the lamina of the leaflets either.

Somehow the aphid causes hypertrophy of the vascular bundles and of the accompanying parenchyma. Based on $1 /$ the similarity between the microscopic composition of the walls of galls induced by G. utricularia and B. pistaciae [10]; and 2/the field observation that the galls induced by $B$. pistaciae concern the leaflet as a whole and not a part of it, the following hypothesis can be formulated: galls induced by $B$. pistaciae may follow a process similar to that of galls induced by G. utricularia. But in this process, $B$. pistaciae would act on the meristematic masses of the bud primordia of $P$. terebinthus. This means that $B$. pistaciae would settle on $P$. terebinthus during earlier stages of development of the leaflets than those in which G. utricularia acts. Microscopic studies and field studies are required to reject or accept this hypothesis.

Moreover, Al-Saghir et al. [16] state that species of the genus Pistacia do not have trichomes. However, in the first of the studies cited above [11] the existence of glandular trichomes on young $P$. terebinthus leaves was established. The same author also noted unicellular nonglandular trichomes at the "entrance" of the galls induced by F. formicaria [9]. In the present study trichomes similar to those induced by F. formicaria are observed. In both cases these should be interpreted as elements that are part of the protection system of the galls against attack by intruders on their interior [17-19].

To summarize the above, it should be underscored that the origin of the two vascular bundles seen in the wall of the galls induced by G. utricularia is found in the interference of the aphid with the normal development of the 
midvein of the leaflets, especially of the two vascular bundles and the surrounding parenchyma cells.

\section{Acknowledgements}

The author wishes to thank to Nicolas Pérez Hidalgo, Antonio Enzina García, Adoración Candelas González and Juan Nieto Nafría for revising the manuscript and Ronald Hartong of TECcientífica for his linguistic assistance. I also thank the Junta de Castilla y León for funding project LE006A09.

\section{REFERENCES}

[1] N. J. Spiller, F. M. Kimmins and M. Llewellyn, "Fine Structure of Aphid Stylet Pathways and Its Use in Host Plant Resistance Studies," Entomologia Experimentalis et Applicata, Vol. 38, No. 3, 1985, pp. 293-295. doi:10.1111/j.1570-7458.1985.tb03534.x

[2] W. F. Tjallingh and T. Hogen-Esch, "Fine Structure of Aphid Stylet Routes in Plant Tissues in Correlation with EPG Signals," Physiological Entomology, Vol. 18, No. 3, 1993, pp. 317-328. doi:10.1111/j.1365-3032.1993.tb00604.x

[3] M. Inbar, "The Evolution of Gall Traits in the Fordinae," In: K. Ozaki, J. Yukawa, T. Ohgushi and P. E. Price, Eds., Ecology and Evolution of Galling Arthropods and Their Associates, Springer-Verlag, Tokyo, 2006, pp. 265-273. doi:10.1007/4-431-32185-3 23

[4] D. Wool, R. Aloni, O. Ben-Zvi and M. Wollberg, "A Galling Aphid Furnishes Its Home with a Built-in Pipeline to the Host Food Supply," Entomologia Experimentalis et Applicata, Vol. 91, No. 1, 1999, pp. 183-186. doi:10.1046/j.1570-7458.1999.00482.x

[5] M. Inbar, M. Wink and D. Wool, "The Evolution of Host Plant Manipulation by Insects: Molecular and Ecological Evidence from Gall-Forming Aphids on Pistacia," Molecular Phylogenetics and Evolution, Vol. 32, No. 2, 2004, pp. 504-511. doi:10.1016/j.ympev.2004.01.006

[6] J. Meyer, "Plant Galls and Gall Inducers," Gebrüder Borntraeger, Berlin, 1987.

[7] M. S. Mani, "Ecology of Plant Galls," Dr. Junk Publisher, The Hague, 1964.

[8] M. Arduin and J. E. Kraus, "Anatomia e Ontogenia de Galhas Foliares de Piptadenia Gonoacantha (Fabales, Mimosaceae)," Boletim de Botânica da Universidade de São Paulo, Vol. 14, 1995, pp. 109-130.

[9] R. Álvarez, A. Encina and N. P. Hidalgo, "Histological Aspects of Three Pistacia Terebinthus Galls Induced by
Three Different Aphids: Paracletus Cimiciformis, Forda Marginata and Forda Formicaria," Plant Science, Vol. 176, No. 2, 2009, pp. 303-314.

doi:10.1016/j.plantsci.2008.11.006

[10] R. Álvarez, "Microscopic Study of the Walls of Galls Induced by Geoica utricularia and Baizongia Pistaciae in Pistacia Terebinthus: A Contribution to the Phylogeny of Fordini," Arthropod-Plant Interactions, 2011, submitted for publication.

[11] R. Álvarez, A. Encina and N. P. Hidalgo, "Pistacia Terebinthus L. Leaflets: An Anatomical Study," Plant Systematic Evolution, Vol. 272, No. 1-4, 2008, pp. 107-118. doi:10.1007/s00606-007-0640-0

[12] B. Ortiz-Rivas, D. Martínez-Torres and N. Pérez-Hidalgo, "Molecular Phylogeny of Iberian Fordini (Aphididae: Eriosomatinae): Implications for the Taxonomy of Genera Forda and Paracletus," Systematic Entomology, Vol. 34, No. 2, 2009, pp. 293-306. doi:10.1111/j.1365-3113.2008.00464.x

[13] M. Martínez-Millán and S. R. S. Cevallos-Ferriz, “Arquitectura Foliar de Anacardiaceae. Leaf Architecture of Anacardiaceae," Revista Mexicana de Biodiversidad, Vol. 76, 2005, pp. 137-190.

[14] D. Wool and N. Bar-El, "Population Ecology of the Galling Aphid Forda Formicaria von Heyden in Israel: Abundance, Demography, and Gall Structure," Israel Journal of Zoology, Vol. 41, 1995, pp. 175-192.

[15] G. Remaudière, M. Inbar, J. Menier and A. Sumida, "Un Nouveau Geoica Gallicole sur Pistacia atlantica en Jordanie Hemiptera, Aphididae, Eriosomatinae, Fordini," Revue Française d'Entomologie, Vol. 26, No. 1, 2004, pp. 37-42.

[16] M. G. Al-Saghir, D. M. Porter and E. T. Nilsen, "Leaf Anatomy of Pistacia Species (Anacardiaceae)," Journal of Biological Sciences, Vol. 6, No. 2, 2006, pp. 242-244. doi:10.3923/jbs.2006.242.244

[17] J. Meyer and J. Maresquelle, "Anatomie des Galles," Ggebrüder Borntrager, Berlin, 1983.

[18] A. T. Simmons, G. M. Gurr, D. McGrath, H. I. Nicol and P. M. Martin, "Trichomes of Lycopersicon spp. and Their Effect on Myzus Persicae (Sulzer) (Hemiptera: Aphididae)," Australian Journal of Entomology, Vol. 42, 2003, pp. 373-378. doi:10.1046/j.1440-6055.2003.00376.x

[19] M. Arduin, G. W. Fernandes and J. E. Kraus, "Morphogenesis of Galls Induced by Baccharopelma Dracunculifoliae (Hemiptera: Psyllidae) on Baccharis Dracunculifolia (Asteraceae) Leaves," Brazilian Journal of Biology, Vol. 65, No. 4, 2005, pp. 559-571. doi:10.1590/S1519-69842005000400002 